
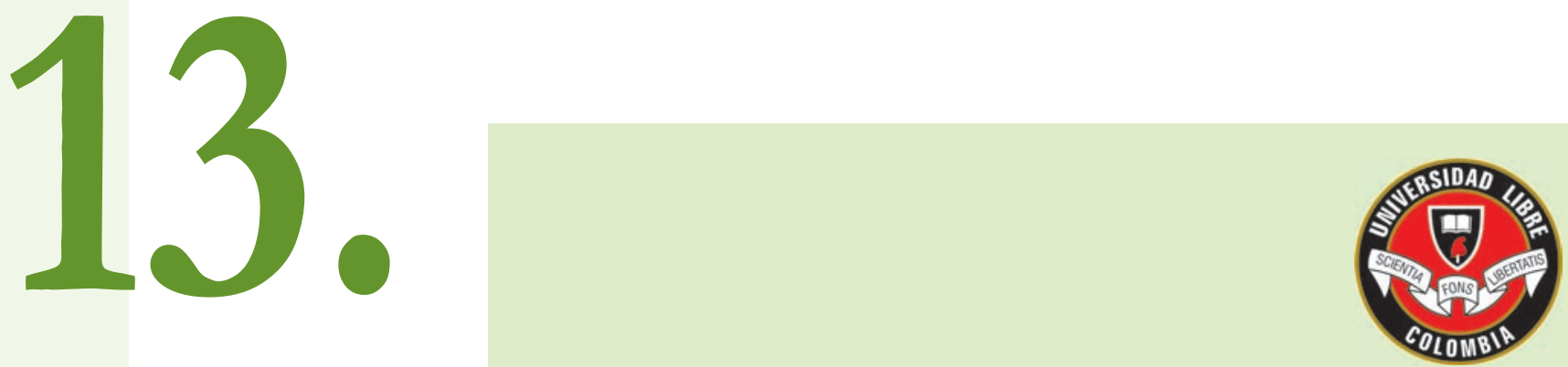

La Calidad Académica, un Compromiso Institucional

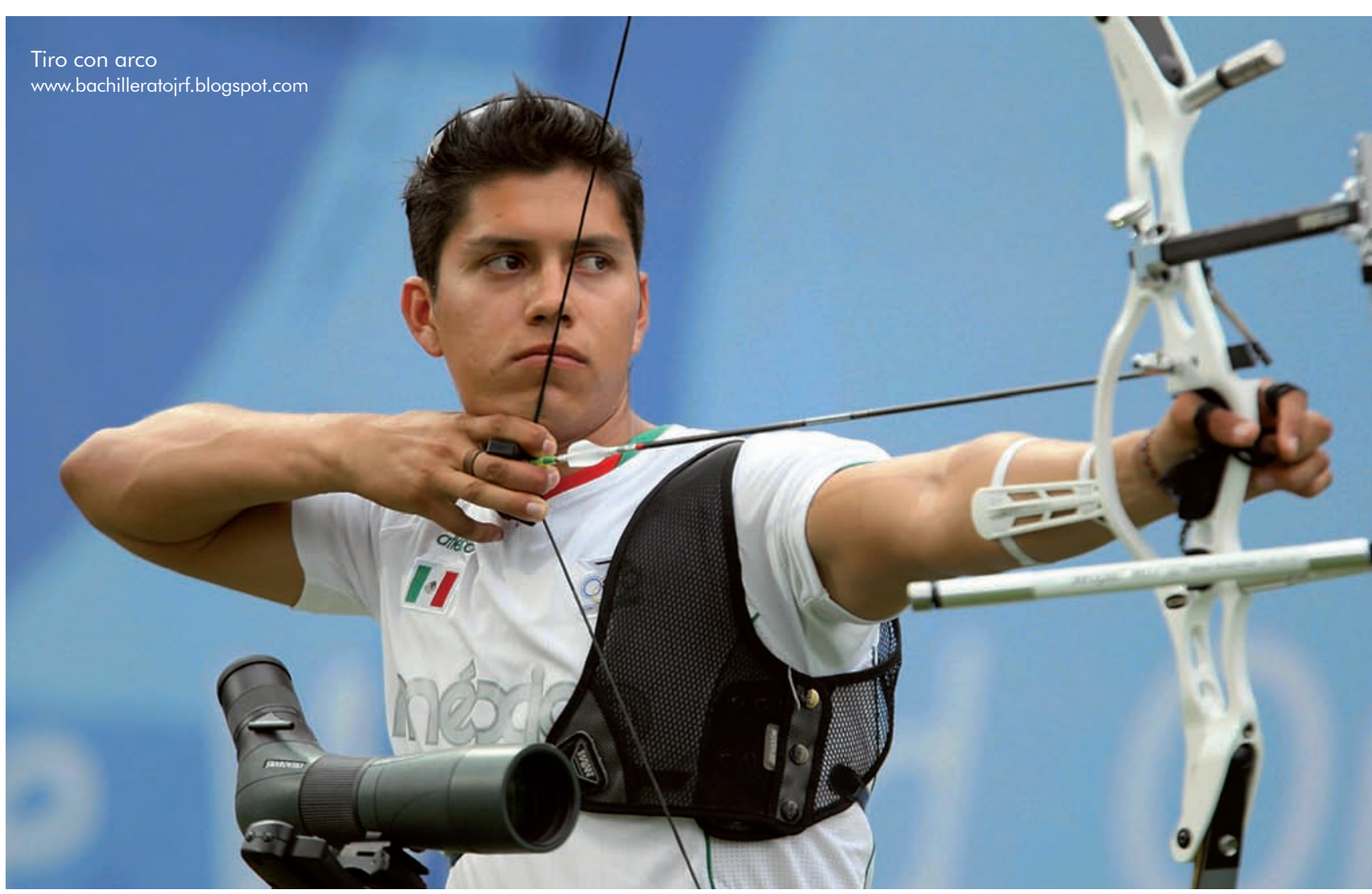

Fajardo C., Constanzo L. y Suárez A., Dora C. (2012). Los impuestos en la época de la Independencia, su impacło social, evolución e implicaciones en el sistema tributario actual. Criterio Libre, 10 (16) 293-316

ISSN 1900-0642
Los impuestos en la época de la Independencia, su impacto social, evolución e implicaciones en el sistema tributario actual

Constanza Loreth Fajardo-Calderón Dora Cecilia Suárez Amaya 


\section{LOS IMPUESTOS EN LA ÉPOCA DE LA INDEPENDENCIA, SU IMPACTO SOCIAL, EVOLUCIÓN E IMPLICACIONES EN EL SISTEMA TRIBUTARIO ACTUAL}

TAXES DURING THE INDEPENDENCE TIMES, SOCIAL IMPACT, EVOLUTION AND IMPLICATIONS ON THE CURRENT TAXATION SYSTEM †

OS IMPOSTOS NA ÉPOCA DA INDEPENDÊNCIA, SEU IMPACTO SOCIAL, EVOLUÇÃO E IMPLICAÇÕES NO SISTEMA TRIBUTÁRIO ATUAL

TAXES À L'ÉPOQUE DE L'INDÉPENDANCE, L'IMPACT SOCIAL, L'ÉVOLUTION ET LES IMPLICATIONS DANS LE SYSTÈME FISCAL ACTUEL

\section{CONSTANZA LORETH FAJARDO-CALDERÓN**/+ DORA CECILIA SUÁREZ AMAYA**/+t+}

\footnotetext{
Artículo producto del Proyecto de investigación "Análisis comparativo de impuestos de carácter nacional del Derecho Tributario de Colombia y el Derecho Tributario de España, en el cual colaboraron, entre otras, las alumnas Leidy Jhoana Moreno, Carolina Carvajal Giraldo y Carolina Montoya Duque.

* Contadora pública, Universidad del Quindío, Armenia, Colombia. Magíster en Educación - Docencia, Universidad de Manizales, Colombia; especialista en Ciencias Tributarias, Universidad del Quindío, Armenia; especialista en Control Fiscal para entidades públicas, Universidad del Quindío, Armenia; Directora de la Especialización en Gerencia Tributaria, Universidad La Gran Colombia, Armenia; docente de planta de la Facultad de Ciencias Económicas y Administrativas, Programa de Contaduría, Universidad del Quindío, Armenia. E-mail: lorethfal@yahoo.es.

*** Contadora pública, Universidad del Quindío, Armenia, Colombia; especialista en Ciencias Tributarias, Universidad del Quindío, Armenia; estudios de maestría en Gestión Empresarial con énfasis en Gerencia Tributaria y Auditoría de Impuestos; docente de la Facultad de Ciencias Económicas y Administrativas, Programa de Contaduría, Universidad del Quindío, Armenia. E-mail: contabilidad@cofincafe.com.
}

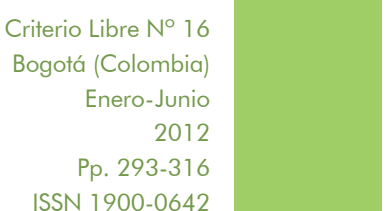




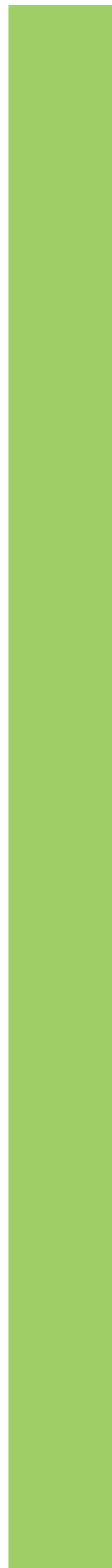

La evolución histórica de los tributos en Colombia se encuentra inmersa en una serie de acontecimientos que hacen parte de la historia patria. El sistema impositivo colombiano fue implementado por España durante la colonización a semejanza del aplicado en dicho país; el incremento de los impuestos para financiar sus actividades y las guerras que sostenía por la lucha de territorios hizo que los habitantes de las colonias se sublevaran en contra del régimen opresor; un claro ejemplo de ello es la rebelión de los Comuneros, la cual se genero debido al incremento del impuesto de la Armada de Barlovento. Los constantes abusos y la discriminación a la que estaban sometidos por parte de los españoles desencadenaron una serie de hechos que posteriormente llevaron a la independencia; al instalarse el nuevo gobierno una de las primeras reformas realizadas en esta materia fue abolir algunos impuestos, como el Tributo de Indios.

Conocer el origen y evolución del sistema impositivo actual en Colombia es de gran utilidad para realizar un estudio más profundo del tema y mejorar la comprensión del mismo, desde un contexto no sólo político y económico sino también social y cultural.

Desde épocas antiguas los tributos han constituido la principal fuente de ingresos del Estado, incluso en la prehistoria estos hacían parte de la religión y sus creencias, lo cual permite evidenciar que han hecho parte de los procesos evolutivos del hombre.

\section{PALABRAS CLAVE:}

Tributos en la Colonia, régimen global de tributos en la Independencia, antecedentes del sistema tributario actual en Colombia.

\section{CLASIFICACIÓN JEL:}

$\mathrm{B} 15, \mathrm{~B} 25, \mathrm{~N} 46$.

+ This article is the product of the "Comparative Analysis of National Taxes in the Colombian Taxation Law and in the Spanish Taxation Law and had the collaboration of the students Leidy Jhoana Moreno, Carolina Carvajal Giraldo and Carolina Montoya Duque, among others.

t† CPA, Universidad del Quindío, Armenia, Colombia. Magister in Education, Universidad de Manizales, Colombia; Sspecialist on Taxation Science, Universidad del Quindío, Armenia; Specialist on Fiscal Control for Public Entitiies, Universidad del Quindío, Armenia; Directora of the Taxation Management Specialization, Universidad La Gran Colombia, Armenia; Professor at Facultad de Ciencias Económicas y Administrativas, Accounting Program, Universidad del Quindío, Armenia. E-mail: lorethfal@yahoo.es.

ttt CPA, Universidad del Quindío, Armenia, Colombia; Sspecialist on Taxation Science, Universidad del Quindío, Armenia; Master studies om Corporate Management focused on Taxation and Tax Audit Management, Professor at Facultad de Ciencias Económicas y Administrativas, Programa de Contaduría, Universidad del Quindío, Armenia. E-mail: contabilidad@cofincafe.com. 


\section{ABSTRACT}

The historic evolution of taxation in Colombia is immersed in a series of events that make part of National history. The domineering Colombian system was implemented by Spain during the colonization following its own model. The increase of taxes to finance its activities and wars held for territories resulted in the uprising of the Colonies inhabitants against the oppressive regime. A clear example is the rebellion of the Communards, which originated due to the tax increase of the Armada de Barlovento.

The constant abuse and discrimination by the Spaniards unleashed the events that lead to the Independence. After the installation of the new government, one of the first reforms made was the abolishment some taxed like the Indian Tribute (Tributo de Indios).

Knowing the origin and evolution of the current imposing system in Colombia is of great help to make a deeper study of the topic and improve its understanding not only from its political context but also the social and cultural one.

From ancient times, taxes have been the main source of the States income. Even in Prehistory, taxes were part of religion and beliefs, which is the evidence to prove that taxes have been part of the evolution process of mankind.

Key words: Colony taxation, global taxation regime during the Independence, Precedents of the current taxation system in Colombia. JEL Classification: B15, B25, N46.

RESUMO

A evolução histórica dos tributos na Colômbia se encontra imersa em uma série de acontecimentos que fazem parte da história pátria. $\bigcirc$ sistema impositivo colombiano foi implementado pela Espanha durante a colonização a semelhança do aplicado em tal país; o incremento dos impostos para financiar suas atividades e as guerras que sustentava pela luta de territórios fez que os habitantes das colônias se insurgiram contra o regime opressor; um claro exemplo disso é a rebelião dos Comuneros, a qual se gerou devido ao aumento do imposto da Armada de Barlovento. Os constantes abusos e a discriminação à que estavan submetidos por parte dos espanhóis desencadearam uma série de feitos que posteriormente levaram à indepêndencia; ao instalar-se o novo governo uma das primeiras reformas realizadas nesta matéria foiu abolir alguno impostos, como o Tributo de Indios.

Conhecer a origem e evolução do sistema impositivo atual na Colômbia é de grande utilidade para realizar um estudo mais profundo do tema e melhorar a compreensão do mesmo, desde um contexto não só político e econômico senão também social e cultural. 


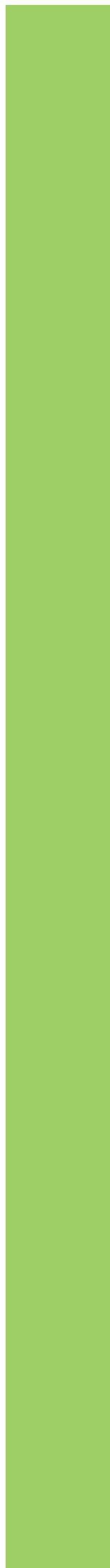

Desde épocas antigas os tributos tem constituído a principal fonte de ingressos do Estado, inclusive na pré-história estes faziam parte da religião e suas crenças, o qual permite evidenciar que tem feito parte dos processos evolutivos do homem.

Palavras chave: Tributos na Colônia, regime global de tributos na Independência, antecedentes do sistema tributário atual na Colômbia.

Classificação JEL: B15, B25, N46.

\section{RÉSUMÉ}

L'évolution historique des impôts en Colombie est plongée dans une série d'événements qui font partie de notre histoire nationale. Le système fiscal colombien a été mis en œuvre par l'Espagne pendant la colonisation. L'augmentation d'impôts pour financer les activités espagnoles et les guerres qu'ils avaient par la lutte des territoires ont fait que les habitants des colonies se révoltent contre le régime oppressif. Un exemple clair, c'est la révolte des communards, qui a été généré en raison de l'augmentation d'impôt du Vent Marine. L'abus et la discrimination constante à laquelle ils ont été soumis par les Espagnols ont déclenché une série d'événements qui ont ensuite conduit à l'indépendance, quand le nouveau gouvernement des premières réformes dans ce domaine a été d'abolir certaines taxes, comme le Tribute des Indiens.

Connaitre l'origine et l'évolution du régime fiscal actuel en Colombie est très utile pour réaliser une étude plus approfondie du sujet et améliorer la compréhension de celvi-ci, à partir d'un contexte politique non seulement économique mais aussi social et culturel.

Depuis les temps anciens, les impôts ont été la principale source de revenus, même dans les temps préhistoriques elles faisaient partie de la religion et les croyances, ce qui permet de montrer qu'ils on fait partie intégrante des processus évolutifs de l'homme.

Mots-clés: Impôts de la colonie, le régime global de taxes à I'indépendance, le système fiscal de fond en cours en Colombie.

Classification JEL: B15, B25, N46.

"Permitir una injusticia significa abrir el camino a todas las que siguen" WILLY BRANDT

\section{INTRODUCCIÓN}

Durante el paso de colonia de España a república, nuestro país experimentó varios cambios en esta materia, dentro de los cuales se ha identificado el 
origen y la evolución que han tenido los diferentes tributos considerados como la principal fuente de ingresos del Estado. Estos en sus inicios hacían parte del sistema tributario español, que los implantó durante la época de la Colonia para sostener y financiar sus actividades bélicas y de conquista territorial.

Con este artículo se pretende hacer una recopilación histórica sustancial de la evolución normativa que han tenido los impuestos más representativos del sistema tributario actual en cuanto a los impuestos de carácter nacional, donde se destacan el impuesto de renta, el impuesto a las ventas, el impuesto de timbre, el impuesto al gravamen financiero y el impuesto al patrimonio. El tema hace parte del trabajo de investigación realizado desde el semillero de investigación de Tributaria SITUQ, "Análisis Comparativo de Impuestos de Carácter Nacional del Derecho Tributario de Colombia y el Derecho Tributario de España", con el cual se conoce el marco histórico de los impuestos en Colombia; se comprenden los sistemas tributarios; se establece el estado del arte de varios impuestos de carácter nacional y se construye un análisis comparativo de sus diferencias y similitudes entre ambos países.

\section{- LA ESTRUCTURA FISCAL DE LA COLONIA'}

Figura 1. Hiijo mestizo de español e india.

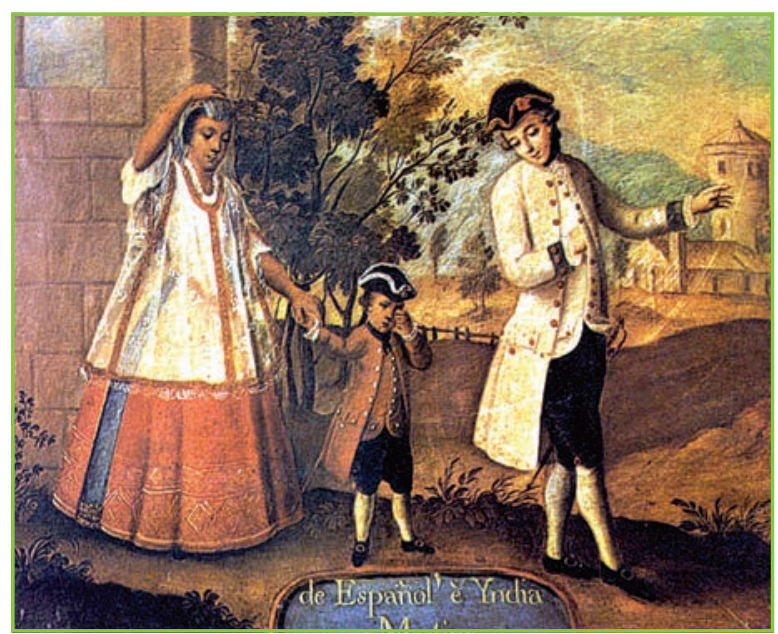

Fuente: Disponible en: http://www.kalipedia.com/fotos/hijomestizo-hijo-espanol.html? $x=20080731 \mathrm{klphishco \_ 9.les.}$

El actual sistema tributario de nuestro país tiene su origen en el sistema tributario de España debido a que después del descubrimiento de América en 1492 este territorio pasó a ser colonia de dicho país.
Según José Hilario Araque Cárdenas en su trabajo "Conceptos básicos de tributación", de la Universidad Sur Colombiana, el sistema tributario establecido por España en las colonias presenta cuatro características esenciales, a saber:

a) Estructura fiscal destinada a extraer el máximo de riqueza de sus colonias en América, diseñando impuestos que le rindieran al máximo sin importar que con ello se afectara el desarrollo económico.

b) Las colonias tuvieron un rendimiento fiscal neto hacia la metrópoli más alto en los comienzos del período colonial que al final del mismo.

c) La excesiva dispersión de los tributos y el alto costo de sus recaudos.

d) El peso de la tributación se puso fundamentalmente en los impuestos de tipo indirecto que entorpecían el comercio entre las colonias, y entre estas y la metrópoli; un factor considerable es la poca importancia que se le dio a la tributación directa.

Araque Cárdenas, José Hilario (2008). Conceptos básicos de tributación. Neiva - Huila, Colombia: Universidad Sur Colombiana - Facultad de Economía y Administración - Programa de Contaduría Pública. Consultado el 14 de septiembre de 2011 . Disponible en: http://www.araqueasociados.com/es/Conceptosbasicosdetributacion.pdf. 


\section{CLASIFICACIÓN 2. DE LOS TRIBUTOS EN LA COLONIA²}

Figura 2. Extracción de oro en tierras colombianas.

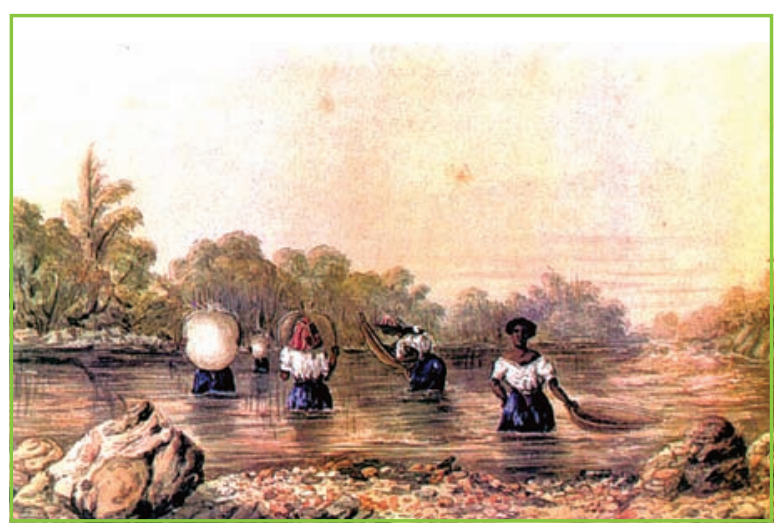

Fuente: Disponible en: http://co.kalipedia.com/ historia- colombia/tema/conquista-colonia/mineria. $h+m \mid ? x=20080730 k$ lphishco_8.Kes\&ap $=2$.

Los tributos en la Colonia se clasificaron en impuestos directos, impuestos indirectos y rentas del monopolio estatal.

\subsection{IMPUESTOS DIRECTOS}

Los impuestos directos, como parte del ingreso que se transfiere al Estado en razón de la propiedad con carácter obligatorio y sin contraprestación, en la Colonia tenían una concepción totalmente distinta, pues implicaban una relación de vasallaje siendo el tributo de indios su expresión por excelencia; era obligación rendir al Estado o a un señor servicios laborales que comprometían su trabajo y su producción económica.

2 Ramírez Plazas, Jaime. "Las finanzas públicas en Colombia", citado por Araque Cárdenas, José Hilario (2008). Conceptos básicos de tributación. Neiva - Huila, Colombia: Universidad Sur Colombiana - Facultad de Economía y Administración - Programa de Contaduría Pública. Consultado el 14 de septiembre de 2011. Disponible en: http://www.araqueasociados.com/es/ Conceptosbasicosdetributacion.pdf.

\section{${ }^{66}$ El actual sistema tributario} de nuestro país tiene su origen en el sistema tributario de España debido a que después del descubrimiento de América en 1492 este territorio pasó a ser colonia de dicho país. 
66

Los impuestos indirectos se caracterizaban por recaer sobre el consumo o una actividad industrial determinada o sobre el comercio.
Los principales impuestos directos durante la Colonia fueron:

a) Tributo de Indias: Este tributo era una contribución personal que los indios debían pagar al rey en reconocimiento del señorío, conforme fue establecido por Carlos V en 1523.

b) Bula de la cruzada: Era una limosna que tenía por objeto financiar la lucha contra los moros y financiar las cruzadas, que buscaban como propósito recobrar la ciudad de Jerusalén; era pagada por la comunidad y a cada ciudad importante del virreinato se le asignaba la suma que debería aportar.

c) Medias anatas: Fue un impuesto directo que debían pagar los oficios eclesiásticos a la Real Hacienda, consistente en la mitad de los ingresos durante el primer año. Felipe IV lo extendió a todos los oficios y cargos, recibiendo la denominación de media anata secular.

d) Mesada eclesiástica: Consistía en una doceava parte de los beneficios obtenidos por el ejercicio de algún cargo eclesiástico, que era equivalente a un mes de ingreso de los clérigos con destino a la Real Hacienda.

e) Espolios: Impuesto que consistía en que los bienes de los arzobispos y obispos al morir pasaban a la Real Hacienda.

f) Vacantes mayores: Tributo consistente en que las rentas provenientes de los oficios eclesiásticos realizadas durante el encargo por la muerte de un clérigo, pasaban a la Real Hacienda.

g) Subsidios eclesiásticos: Era un impuesto con carácter provisional que pagaban los eclesiásticos para atender ciertas urgencias del reino; posteriormente se estableció con carácter permanente bajo el nombre de subsidio de Galeras, como gravamen destinado a mantener la flota de galeones que cuidaba las costas españolas de los ataques bélicos.

h) Enajenación de oficios o cargos públicos: Los principales cargos y oficios eran rematados en pública subasta por aquellos que tenían las condiciones mínimas para desempeñarlos, llegando a constituir un ingreso importante de la Real Hacienda. 
i) Donativos graciosos: Esta era una contribución extraordinaria y forzosa que en distintas épocas y con destino particular se decretó, haciéndola aparecer como un servicio gracioso y voluntario con que se acudía al alivio de las urgencias y necesidades del reino. Este fue uno de los impuestos que motivaron el levantamiento de los comuneros ${ }^{3}$.

Según Salomón Kalmanovitz (2008) ${ }^{4}$, este impuesto equivalía a 2 pesos por noble y 1 peso por plebeyo y debía ir directamente al rey, por lo cual se sospechaba iba a ser aplicado graciosamente en forma permanente.

\subsection{IMPUESTOS INDIRECTOS}

Los impuestos indirectos se caracterizaban por recaer sobre el consumo o una actividad industrial determinada o sobre el comercio. Los principales impuestos indirectos durante la Colonia fueron ${ }^{5}$ :

a) Diezmos: "Consistía en un gravamen del $10 \%$ que se aplicaba sobre la producción agrícola, y que tenía como propósito financiar el mantenimiento del culto y de sus prelados en América. Una parte menor del diezmo (dos novenos) ingresaba directamente a las arcas de la Real Hacienda y no estaba afectada al mantenimiento del culto. Por lo general, el tributo del diezmo se pagaba en frutos"6.

b) Quinto real: "Con este nombre se conoció el gravamen que recaía sobre la explotación de los minerales preciosos en América. En Castilla, durante la Edad Media, el gravamen sobre el oro era de dos tercios, pero para estimular la explotación de los recursos minerales de las nuevas tierras, este porcentaje fue rápidamente reducido. Entre 1500 y 1504 , en respuesta a las peticiones formuladas por los colonizadores de la isla La Española, fue reducido sucesivamente a un medio, a un tercio, y finalmente a un quinto. Este quinto real o el quinto, como se le llamó en los archivos de la Real Hacienda, fue establecido por 10 años, por decreto del 5 de febrero de 1504 y permaneció hasta el siglo XVIII como la ley general de todas las Indias. Como la productividad de las minas no era la misma en las diversas regiones de América, y como a medida que fue declinando la producción de ciertos yacimientos fue necesario estimular la producción de otros menos ricos, el quinto real no fue inmodificable, sino que las autoridades de las diversas provincias recibieron autorización para regular su monto de acuerdo con la productividad de las minas y para contrarrestar el contrabando"7.

c) Ventas de tierras realengas: "Puede mencionarse como otro ingreso de la corona de gran importancia. Se consideraba que en virtud de la bula del 4 de mayo de 1943 del Papa Alejandro VI, que otorgó a la corona de Castilla todas las tierras descubiertas en América, estas pertenecían a la corona. Aquellas que no fueron otorgadas en merced o concesión fueron vendidas, y el producido de estas ventas constituyó un ingreso de importancia para la corona" ${ }^{\prime 8}$.

d) Avería: "Consistía en una especie de derecho de aduana que gravaba las mercaderías enviadas de España a las colonias o viceversa. Posteriormente fue establecido el Almojarifazgo, que cumplía la misma función" ${ }^{\prime \prime}$.

3 Araque Cárdenas, José Hilario (2008). Conceptos básicos de tributación. Neiva - Huila, Colombia: Universidad Sur Colombiana - Facultad de Economía y Administración - Programa de Contaduría Pública. Consultado el 14 de septiembre de 2011 . Disponible en: http://www.araqueasociados.com/es/Conceptosbasicosdetributacion.pdf.

4 Kalmanovitz, Salomón (2008). Consecuencias económicas del proceso de Independencia en Colombia, Bogotá: Fundación Universidad de Bogotá Jorge Tadeo Lozano.

lbíd., p. 13.

Restrepo, Juan Camilo (2001). "Hacienda Pública", en: Ingresos fiscales, p. 66.

Ibíd.

lbíd., p. 67.

Tirado, Álvaro (1977). Introducción a la Historia Económica de Colombia. Medellín: La Carreta, p. 74. 
Se comenzó cobrando el $2.5 \%$ sobre el valor de las mercancías, aunque el porcentaje no dejaría de crecer desde 1587, con el aumento de las amenazas de los piratas ingleses; en ocasiones se llegó al 30\%. El impuesto dejó de cobrarse en 1660 ante el fraude generalizado y el contrabando, que atentaban contra su buena gestión, dado que al final lo que se pagaba era una cantidad general en función de la carga estimada en concepto de amnistía y no un porcentaje sobre el valor real de las importaciones. De esta manera, fue el derecho de aduana sobre artículos que se importaban o se exportaban del país ${ }^{10}$.

e) Almojarifazgo: Era un impuesto que se cobraba a las mercancías en los puertos, equivalente a lo que hoy llamamos impuesto de aduanas ${ }^{11}$.

f) Alcabala: Tributo establecido sobre el comercio de los bienes muebles e inmuebles y semovientes. "Alcabala es una palabra de origen árabe, que sirve para designar el derecho que en España se exigía sobre el valor de todas las cosas muebles e inmuebles y los semovientes que se permutaban o vendían. En América tuvo una tarifa del $2 \%$ sobre el valor de dichas transacciones, aunque en España fue del 10\%. Según la cédula real de Felipe II del 7 de julio de 1576, debían pagar este impuesto todo género de personas, con las excepciones hechas por las leyes, de la primera y todas las demás ventas, trueques y cambios, así como de las mercaderías procedentes de España y de las que hubiera, se labraran y fabricaran en Indias, a razón del 2\% en dinero de contado"12.

g) Armada de Barlovento: Fue un impuesto equivalente a un porcentaje del impuesto de alcabala y con destino al mantenimiento de la Armada de Barlovento, que tenía como función proteger a las flotas españolas contra los ataques de los corsarios.

h) Derecho de puertos: Este impuesto fue establecido a las embarcaciones por el derecho a utilizar los puertos en América.

i) Impuesto de bodegas: Se estableció este impuesto al comercio exterior por el uso de las bodegas en los puertos para el almacenamiento de mercancías.

i) Pasos reales: Impuesto establecido por el uso de los caminos reales equivalentes a lo que hoy conocemos con el nombre de peajes.

k) Rentas estancadas: Se conoce con este nombre el conjunto de ingresos provenientes de las actividades industriales y comerciales realizadas por la Corona a través del establecimiento de monopolio para generar rentas tendientes al sostenimiento de la Corona y como consecuencia de la disminución de la tributación.

Los monopolios más importantes establecidos durante la Colonia fueron los del papel sellado, del tabaco, del aguardiente, de la pólvora y del platino"13.

\subsection{OTROS TRIBUTOS DE LA ÉPOCA}

a) Sisa: Era el porcentaje de peso y medida, que el vendedor sustraía al comprador, en las transacciones menores, en beneficio de la Corona ${ }^{14}$.

Según José Ignacio de Pombo en el "Informe del Consulado de Cartagena sobre asuntos económicos y fiscales", otros tributos de la época eran los siguientes ${ }^{15}$ :

b) Derechos de exportación: Estos derechos tenían una tarifa de $2 \frac{1}{2} 2$ y de $4 \frac{1}{2} 2$ por 100 ;

10 Consultado el 14 de septiembre de 2011. Disponible en: http://vivivanaandreamolina903.blogspot.com/2010/10/ actividad-que-son-transacciones.html.

11 Tirado, Álvaro. Op. cit., p. 74.

12 Restrepo, Juan Camilo (2001). Hacienda pública, en ingresos fiscales. Bogotá - Colombia, p. 71.

13 Araque Cárdenas, José Hilario (2008). Conceptos básicos de tributación. Neiva - Huila, Colombia: Universidad Sur Colombiana - Facultad de Economía y Administración - Programa de Contaduría Pública, p. 15. Consultado el 14 de septiembre de 2011 . Disponible en: http://www.araqueasociados.com/es/Conceptosbasicosdetributacion.pdf.

14 Tirado, Álvaro. Op. cit., p. 74.

15 De Pombo, José Ignacio (1807, 18 de abril). "Informe del Consulado de Cartagena sobre asuntos económicos y fiscales" (1920), en: Boletín de Historia y Antigüedades, año XIII, No. 154, pp. 689-698. 
se cobraba además de los municipios, sobre los frutos del país cuando se extraían para el interior, o para otros puertos de la América española, y de 91/2 por 100 si su extracción era para los extranjeros, sobre precios corrientes, y con exclusión también del 1 1 1/2 de subvenciones, y $1 / 2$ de consulado.

Las producciones agrícolas y las carnes estaban gravadas con el derecho a contribución del diezmo, con la primicia, con la alcabala, la sisa, los gastos de conducción al puerto y los de transporte, etc.; dichas contribuciones aumentaban su valor, el cual ascendía a $11 \frac{1}{2}$ por 100, lo cual dificultaba su venta en los países extranjeros.

c) Derechos de tierras: Se cobraban por los ministros de la Real Hacienda, a título de venta, composición y arriendo de tierras realengas. Estas y todas las que había abandonadas en la provincia debían concederse gratuitamente y en porciones proporcionadas, a cuantos las solicitaran, con la obligación de cultivarlas o poblarlas de ganados, dentro de un preciso término, que no excediera tres años, pasados los cuales, si no cumplían con la condición dicha, podían adjudicarse a otras personas.

d) Derecho de mazamorreros: Este se cobraba a los llamados mazamorreros, que se dedicaban a sacar oro de las orillas de los ríos y quebradas, a razón de cuatro pesos por cada año, sacaran o no el metal, y aunque trabajaran un solo día del año.

e) Derecho de subvención de guerra: Este derecho se cobraba en la aduana con una tarifa de $1 \frac{1}{2}$ por 100 sobre los frutos, y $1 / 2$ por 100 sobre la plata y oro a título de subvención de guerra, con el objeto de socorrer a España en la guerra contra los franceses.

f) Toneladas: El derecho de toneladas se cobraba en las embarcaciones nacionales a título de almirantazgo, el cual se exige de ellas por la marina.

g) Anclaje: El derecho de anclaje se exigía a las embarcaciones y se aplicaba también al almirantazgo; tenía como destino prevenido por la ley municipal, la sustentación de los lazarinos, y se cobraba en el puerto sobre las embarcaciones de quilla únicamente.

\section{6 Alcabala es una palabra de origen árabe, que sirve para designar el derecho que en España se exigía sobre el valor de todas las cosas muebles e inmuebles y los semovientes que se permutaban o vendian.}


66

Pese al abigarrado número de impuestos, el sistema no producía al Estado colonial ingresos adecuados para cumplir muchas de sus obligaciones. En general, el fisco colonial sólo producía para mantener una burocracia mal pagada e ineficiente, para sufragar los cuantiosos gastos militares causados por el constante estado de guerra que España mantenía frente a Inglaterra y Francia, y finalmente, para unos pocos gastos en servicios. La noción de servicio público prácticamente no existía, ni los ingresos públicos eran suficientes para adelantar obras de beneficio común. h) Sanidad: Esta contribución se cobraba a las embarcaciones con el título de Visita de Sanidad.

i) Registro: Este derecho se cobraba en los despachos, sobre los registros de los buques de comercio. Estos debían componerse de las hojas o partidas originales de los interesados, que debían presentar por duplicado o triplicado según conviniera en la Aduana; el escribano le otorgaba la escritura de fianza en su registro público, y autorizaba el abordaje de sus tripulantes; el mayor registro no podía pasar de tres pesos; y todo cuanto se cobraba con título de testimonio, de copias y demás diligencias, era un abuso que no solo aumentaba los costos de la navegación sino que la dificultaba, y hacia lenta con arbitrarias detenciones y con mucho perjuicio del comercio, cuyas principales ventajas consistían en la celeridad de sus operaciones.

i) Certificaciones: Los dueños o sobrecargos de las embarcaciones, para poder ser despachadas por el gobierno, debían presentar certificaciones de los ministros reales, en las cuales constaba que no eran deudores a la Real Hacienda ni a la Aduana.

k) Pertrechos marítimos: Era un gravamen para la navegación, el cual aumentaba en gran medida los fletes.

Según Jaime Jaramillo Uribe en "La estructura del sistema fiscal español"16, se caracterizaba por ser oneroso para los diversos sectores productivos, y se convirtió en una de las más fuertes motivaciones de la revolución comunera de 1781 y posteriormente del movimiento de Independencia. Sin embargo, tuvo que ser conservado por los gobiernos republicanos en sus aspectos esenciales y sólo vino a ser sustituido a partir de 1850.

El sistema se caracterizaba por una compleja red de impuestos indirectos y monopolios fiscales

16 Jaramillo Uribe, Jaime (1987). "La economía del Virreinato (1740-1810)", en: Ocampo, José Antonio (comp.). Historia Económica de Colombia, Bogotá: Fedesarrollo - Siglo XXI Editores, pp. 77-78. 
como los de aguardientes, tabaco, sal, naipes, pólvora $y$, al finalizar la época colonial, otros como el de exportación del palo de tinte y el de la quina, de corta duración.

Estos estancos o monopolios, especialmente el de aguardientes y tabaco, fueron el blanco de las mayores críticas porque restaban campos de actividad a comerciantes y agricultores, que estaban en capacidad de hacer inversiones y explotar por su cuenta la siembra, la producción y el mercadeo. Se los consideraba la mayor restricción a la libertad de comercio, que ya empezaba a ser una de las aspiraciones de hacendados y comerciantes y el más claro ejemplo de la política monopolista del gobierno español.
Pese al abigarrado número de impuestos, el sistema no producía al Estado colonial ingresos adecuados para cumplir muchas de sus obligaciones. En general, el fisco colonial sólo producía para mantener una burocracia mal pagada e ineficiente, para sufragar los cuantiosos gastos militares causados por el constante estado de guerra que España mantenía frente a Inglaterra y Francia, y finalmente, para unos pocos gastos en servicios. La noción de servicio público prácticamente no existía, ni los ingresos públicos eran suficientes para adelantar obras de beneficio común (como caminos, educación, salud y beneficencia). Había en realidad una multiplicidad de cargas tributarias "engorrosas y complejas".

\section{IMPUESTOS EN LA INDEPENDENCIA DE COLOMBIA}

Figura 3. Libertador Simón Bolívar.

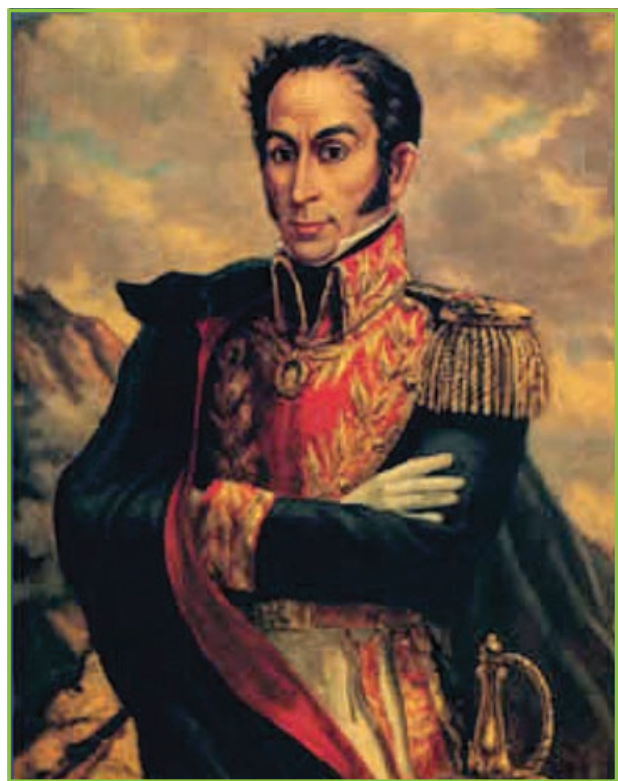

Fuente: Disponible en: http://www.venezuelatuya.com/ biografias/bolivar.htm.
Luego del paso de colonia a república, durante la Independencia, según Hermes Tovar (1987), en "Los cambios en el terreno fiscal en la Republica"17, uno de los aspectos más controvertidos durante la constitución y desarrollo del Estado republicano fue el relativo a las rentas. Esto a causa del desorden introducido por la guerra y las medidas adoptadas en los primeros años de la República, lo cual había creado traumas en la estructura tributaria. La supresión de algunos impuestos y la desorganización de la administración fiscal abrieron un boquete considerable en los recursos del Estado, al tiempo que aumentaban notablemente las necesidades de gasto.

Las nuevas demandas creadas por la Independencia tenían tres orígenes diferentes. El primero era la aparición de un ejército nacional, que no solamente debía garantizar el triunfo republicano sino que debió hacer frente a la resistencia irregular que sobrevivió después de

17 Tovar, Hermes (1987). "La lenta ruptura con el pasado colonial (1810-1850)", en: Ocampo, José Antonio (ed.). Historia Económica de Colombia. Capítulo III, Bogotá: Fedesarrollo - Siglo XXI, pp. 91-94. 
1820. La Nueva Granada tuvo también que financiar los ejércitos que se enviaron al sur de América para luchar por la independencia de Ecuador y Perú. A esto se unieron los levantamientos, las guerras civiles y las amenazas de reconquista.

Después de la reorganización del sistema rentístico que emprendieron las autoridades españolas durante la Reconquista, los primeros gobiernos y congresos republicanos adoptaron una actitud más cautelosa.

En 1821 el Congreso de Cúcuta abolió algunas rentas menores que se consideraban particularmente opresivas, entre ellas nuevamente el tributo de indios y el impuesto a los mazamorreros, la alcabala para ventas internas (aunque se mantuvo, con una tasa reducida, para las operaciones de propiedad raíz), el impuesto sobre las ventas de víveres o sisa y la venta de cargos públicos. Sin embargo, por razones estrictamente rentísticas se mantuvieron los monopolios estatales sobre el tabaco y la sal, pese a la oposición que existía contra el primero, y se sustituyó el del aguardiente por un gravamen diferente. Además, los diezmos y el quinto también se preservaron, pese a que se consideraban verdaderos frenos al desarrollo de la agricultura y la minería nacional.

El ensayo más interesante en el terreno fiscal en los primeros años de la República fue el establecimiento de un impuesto a la renta. Este nuevo gravamen, creado en 1821 en el Congreso de Cúcuta, tenía dos modalidades. En el caso de los salarios, se trataba de un gravamen levemente progresivo: nulo para rentas inferiores a $\$ 150$ anuales, de $2 \%$ para ingresos de entre $\$ 150$ y $\$ 1.000$, y de 3\% para rentas superiores. Para los ingresos de capital, el gravamen era de $10 \%$, sobre una base que era en la práctica una renta presuntiva, pues equivalía a $5 \%$ de los capitales invertidos en la agricultura, la minería y la manufactura (incluidos los terrenos), y a $6 \%$ de los invertidos en el comercio. El gravamen funcionó en forma muy deficiente en ausencia de un catastro que sirviera para determinar, siquiera imperfectamente, el valor de las propiedades. Su producido resultó ser apenas una ínfima porción de lo estimado inicialmente. Fue suspendido temporalmente en 1823 y, después de una tentativa de mejorarlo, quedó abolido definitivamente en 1826.

Afirman Fajardo y Suárez (2010, p. 14) que: "Desde el Grito de Independencia en 1810 hasta el momento en que ésta se consolida con la Batalla de Boyacá, se dictan cinco constituciones para Tunia, Antioquia, Cartagena y Mariquita; en todas ellas se establece la facultad del poder legislativo de uasignar contribuciones que deban pagarse por los pueblos, el modo como deben cobrarse y sobre los ramos que deban imponerse»".

No era fácil cobrar impuestos porque las personas consideraban que precisamente se habían independizado para no tener que pagarlos, por ello en ocasiones los gobernantes preferían acudir al crédito externo motivados por la urgencia de recursos y por la disminución en las rentas debido a la supresión de los impuestos coloniales. Nuestro país no podía escapar a la situación antes descrita, pues los tributos "eran considerados pillaje organizado y esa actitud se transfirió a los impuestos establecidos por los estados independientes. Sin embargo, correspondía a buenos principios liberales bajar los impuestos para liberar las fuerzas del mercado y facilitar la acumulación de capital en el sector privado"18.

A pesar de lo anterior, a medida que avanza el proceso de conformación de la República el sistema tributario se va acomodando a las

18 Consultado el 10 de marzo de 2011. Disponible en: http://www.unilibre.edu.co/CienciasEconomicas/Webcontaduria/ estudie. 
nuevas circunstancias, siempre bajo la influencia europea líder en estas materias, pero con alta dependencia de las rentas del comercio exterior.

Figura 4. Artesano del siglo XIX en un telar.

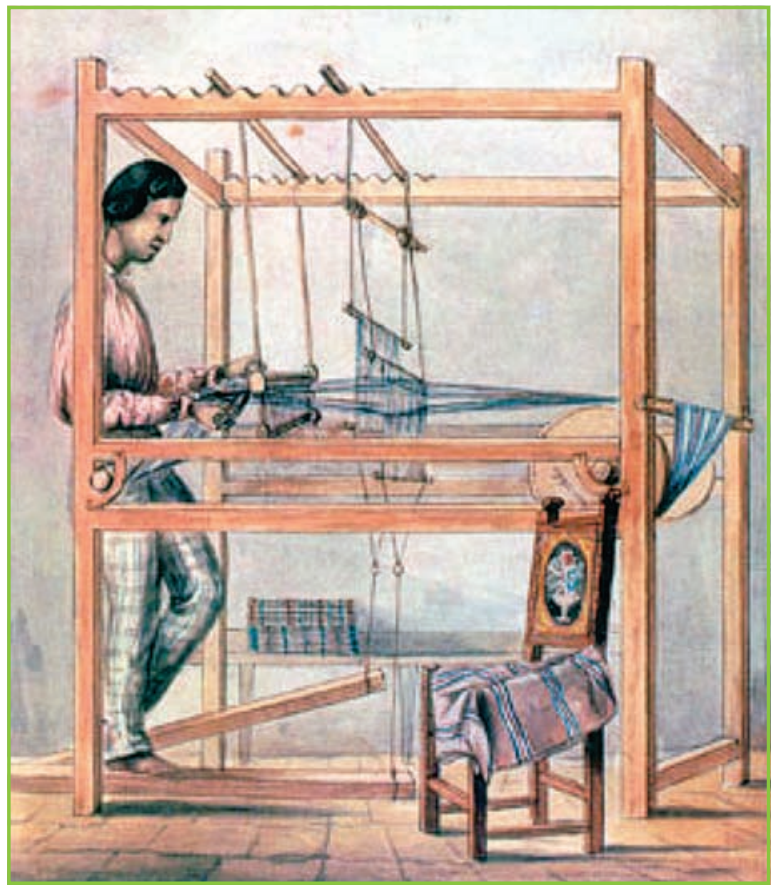

Fuente: Disponible en: http://co.kalipedia.com/historiacolombia/tema/siglo-xix-colombiano/artesanos.

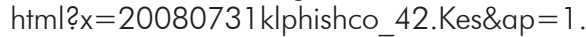

\section{COLOMBIA - RÉGIMEN . GLOBAL DE TRIBUTOS, $1823^{19}$}

La estructura de los ingresos públicos por aquella época era completamente proveniente de impuestos al consumo. Sobresalen allí los impuestos de:

a) Aduanas: Este gravamen era considerado como la renta directa de mayor rendimiento fiscal y estaba conformada por: a) Pago de patente o nacionalización de barcos

19 López Garavito, Luis Fernando (1992). Historia de la Hacienda y el tesoro en Colombia. Bogotá: Banco de la República, pp. 34-38.
66 No era fácil cobrar impuestos porque las personas consideraban que precisamente se babian independizado para no tener que pagarlos, por ello en ocasiones los gobernantes preferian acudir al crédito externo motivados por la urgencia de recursos y por la disminución en las rentas debido a la supresión de los impuestos coloniales." 
Figura 5. Hacienda del siglo XIX.

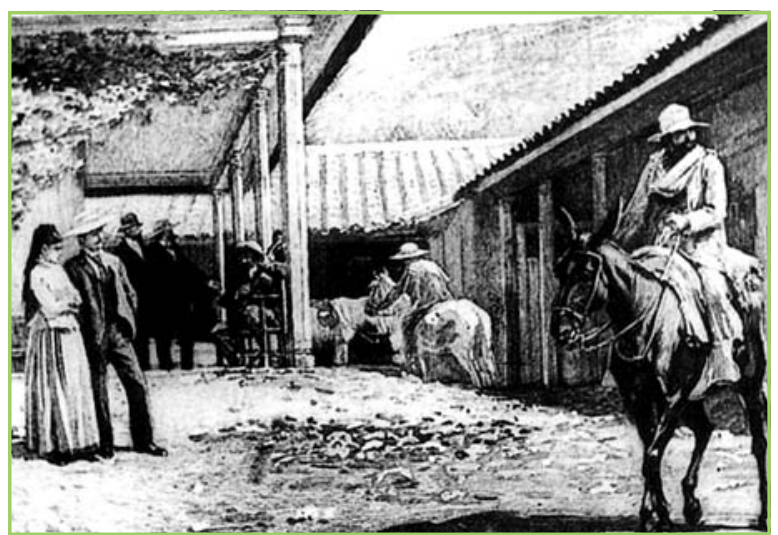

Fuente: Disponible en: http://co.kalipedia.com/historiacolombia/tema/siglo-xix-colombiano/economia-republica. htmlex $=20080731$ klphishco_21.Kes.

extranjeros; b) Pago por derechos de importación (fiijado desde el régimen español); c) Pago de derechos de exportación (fijado desde el régimen español); d) Derechos de toneladas (equivalente a medio peso por tonelada en buque extranjero y un real nacional).

posteriores se cambió por renta de arrendamiento en atención a los elevados costos de aparatos, bornillas, calderas y acueductos que el gobierno en sus limitaciones financieras no podía renovar

y mantener. b) Tabacos: Este era un estanco o monopolio de la República. Las factorías registraban cosecheros particulares, quedando estos obligados a vender la hoja exclusivamente a esas dependencias. La red se completaba con los estancos o puntos de venta del producto. Generalmente las compras de hoja por el Estado sufrían reducciones importantes por la escasez de numerarios, con lo cual el gobierno no podía sostener un crecimiento permanente del cultivo donde éste actuaba como monopsonista o único comprador. De la venta global se descontaban los costos de administración y compra de la hoja y la diferencia era renta fiscal para el tesoro público.

c) Salinas: Por leyes especiales las minas de sal en el territorio se declararon propiedad del Estado, monopolio con el cual la Nación se sostuvo durante muchas décadas. La explotación directa se mantuvo y sólo en años posteriores se cambió por renta de arrendamiento en atención a los elevados costos de aparatos, hornillas, calderas y 
acueductos que el gobierno en sus limitaciones financieras no podía renovar y mantener.

d) Amonedación: Bajo este nombre se estableció desde la Colonia los recaudos originados en las utilidades que dejaban las casas de moneda de la Nación, y los derechos de quintos y fundiciones. Hacia 1823 existían dos casas de moneda, una en Bogotá y otra en Popayán. La ley del 29 de septiembre de 1823 ordenó a estas casas la producción de monedas de oro con las nuevas armas de la República, doblones que se exportaron y fueron de mucha aceptación en otros países, tal como lo expresó el secretario de Hacienda en 1823. Sin embargo, el tesoro público recibía muy pocos rendimientos de estas operaciones ya que el contrabando del metal precioso era manifiesto.

e) Papel sellado: Renta generalizada en el siglo XIX en varios países. Se pagaba sobre los contratos y actos civiles que se hacían públicos. El papel sellado se clasificaba en cuatro sellos que a su vez tenían subdivisiones y naturalmente, precios diferentes. Se empleaban para actuaciones específicas con arreglo a leyes de los años 1811 y 1813. Los precios de los diferentes sellos variaron en 1826 entre 8 y 2 pesos, empleándose en documentos de funcionarios públicos, en la fundación de ciudades o poblados, para patentes de navegación, para dar testimonios, para actos judiciales, para letras de cambio, para pasaportes, para la primera hoja de los libros de comerciantes, y para suscribir obligaciones superiores a 100 pesos, entre otros.

f) Alcabalas: Impuesto que quedó vigente sólo para transacciones de finca raíz, y de todos modos se suprimió después por la voluntad férrea del secretario de Hacienda que nunca compartió el gravamen ya que lo consideraba usurero y causante de la postración económica de la Nación.

g) Aguardientes: La producción y comercialización de aguardientes fue monopolizada durante el antiguo virreinato de la Nueva Granada. Una vez se independizaron las provincias y la Nueva Granada y Venezuela conformaron la República de Colombia, se encontró que Venezuela no tenía establecido el monopolio, creando en su lugar un régimen de control a los alambiques, estableciendo la prohibición de importar licor extranjero y estableciendo un gravamen en favor del tesoro nacional por venta al detal del producto. Se mantuvo posteriormente como un monopolio de las rentas regionales.

h) Diezmos: Contribución que gravaba la agricultura y la ganadería, tenía por objeto principal la subsistencia de las comunidades religiosas, seminarios y conciliares. Se cobraba a través de los rematadores que controlaban el recaudo y liquidación del diezmo. El tesoro público recibía del total de esta contribución una novena parte, más dos novenas de la mitad del total del gravamen, tal como lo dejó montado el régimen español antes de 1810, y que la autoridad local refrendó con decreto del 15 de octubre de 1811.

i) Correos: Más que un gravamen, se contemplaba como un servicio vital del Estado, y que para su desarrollo reclamaba más gastos en modernización de vías, que la iliquidez del tesoro público no podía ofrecer. Los correos tenían en la época cuadras de caballos y coches con conductores, valijas para protección de las cartas, barcos para transporte acuático y cruce de ríos, y estafetas encargados de la distribución de la correspondencia. Este patrimonio personal entraba en lucha continua con el deterioro de los caminos descuidados por el régimen español y por la guerra. Además la pequeña retribución a los estafetas determinaba un reparto tardío de las comunicaciones, ya que ellos buscaban otras fuentes de trabajo, disminuyendo su atención en el servicio público ofrecido.

Venduta: Gravamen nacido del derecho de ofrecer en plaza pública la venta de bienes. Llamado también moneda pública, se estableció en la naciente república mediante decreto del 14 de marzo de 1822. Su número fue limitado por carencia de presupuesto para montar más plazas de ventas estatales, razón que limitaba el rendimiento de este gravamen en favor del tesoro público. 


\section{LA Situación Fiscal en la Época de LA República}

\subsection{PERÍODO DE 1810 A 1850}

La situación fiscal a comienzos de la República se mantuvo igual a la presentada durante la Colonia, e incluso se restableció el estanco de aguardiente en algunas comarcas donde había sido abolido; todo esto ocurrió con la voluntad del libertador Simón Bolívar, quien consideraba que la nueva república necesitaba recursos para su organización.

Superada esta etapa de búsqueda de orden político y fiscal, al concluir la campaña libertadora tan pronto como se obtuvo la independencia de España en 1820 en el gobierno de Francisco de Paula Santander se establece la contribución directa (impuesto sobre la renta) tomado del modelo inglés, pero a raíz de las continuas guerras civiles y como se indicó antes, no fue posible su implementación.

En 1821 en el Congreso de Cúcuta se comienza a hacer algunas modificaciones de importancia en la estructura fiscal heredada de la Colonia ${ }^{20}$.

Los principales cambios que introdujo fueron: se suprimieron básicamente los siguientes impuestos: la alcabala, quedando sólo vigente para unas pocas transacciones de bienes inmuebles y para productos alimenticios 0 industriales cuando se trataban de mercancías extranjeras; el impuesto de la sisa; el tributo indígena; el monopolio del aguardiente; la venta de empleos; el monopolio de naipes y se abolió el tributo a la población indígena.

Afirma David Bushnell (1995, p. 85) que "El Congreso de Cúcuta reafirmó e hizo extensiva a toda la República la liquidación de los resguardos, que ya habían decretado algunas de las provincias de la Nueva Granada". Para recompensar la desaparición de la Alcabala, el congreso decidió experimentar atrevidamente un régimen de impuestos directos, que recaudaría el $10 \%$ de los ingresos producidos por la tierra o el capital. En lugar del tributo, declaró a los indígenas ciudadanos iguales en derechos, obligándolos ahora a pagar los demás impuestos de los que antes estaban exentos.

Aunque las obligaciones que generaban las alcabalas eran ahora más bajas que antes, su totalidad se pagaba en los puertos suramericanos, lo cual aumentaba el ingreso local, ya que anteriormente una parte de ellas se desembolsaba en España.

A partir de esa fecha y hasta que se crea el impuesto a las ventas en 1965, el impuesto de aduanas era el impuesto indirecto más importante del país pero no suficiente para satisfacer la necesidad de recursos del Estado.

\subsection{PERÍODO DE 1850 A 1930}

Con la llegada de los radicales al poder se inicia la eliminación de buena parte de los impuestos que caracterizaron el período español y el surgimiento de la tributación directa en Colombia, manteniendo sólo tres grandes impuestos, a saber: aduanas, las salinas y el papel sellado.

Según los historiadores, la Independencia logró acabar con la monarquía española en América y abrió el camino para el desarrollo de una historia republicana. El proceso de independencia significó también cambios sustanciales en la sociedad y en la economía de las naciones americanas, incluida la Nueva Granada.

20 Araque Cárdenas, José Hilario (2008). Conceptos básicos de tributación. Op. cit., p. 16. 
Los comerciantes neogranadinos, después de la independencia se vincularon con el comercio internacional, a través de los ingleses, con menos restricciones. Exportaron una mayor cantidad de productos agrícolas. Sin embargo, lo que primó desde sus comienzos fue un intercambio comercial desigual para la recién conformada república. Llegaban más productos del extranjero, mercancías manufacturadas de Inglaterra, que lo que la Nueva Granada podía vender en otros países. Es decir, se importaba más y más caro que lo que se exportaba.

El Estado republicano tuvo que construir su propia base burocrática fuera de los marcos coloniales, lo que implicó un aumento en los funcionarios con la existencia de instituciones como el Congreso, entre otros organismos propios de un sistema republicano. En este sentido, además, el Estado se encontró con la disyuntiva de cambiar o preservar el antiguo sistema fiscal y tributario de la Colonia. Cuestión que se pudo resolver a mediados del siglo XIX.

Los primeros treinta años del siglo XX son la historia permanente de las crisis fiscales generadas por las caídas del impuesto de advanas resultado de la crisis del comercio exterior que impedía la exportación de café, quina, tabaco, o de las importaciones, resultado de la Primera Guerra Mundial.

Ante esa situación, se empezó a ver la urgencia de implantar el impuesto directo a la renta bajo la iniciativa del entonces ministro de Hacienda, el doctor Esteban Jaramillo, considerado el padre de la hacienda pública en Colombia, como mecanismo que haría depender las finanzas públicas de la tributación directa generada en Colombia, y no de las fluctuaciones del comercio exterior. Por medio de la ley 56 de 1918 se estableció el impuesto directo a la renta, que grava a cada uno según su capacidad, sirviendo un instrumento financiero como un ideal social, pues permite consultar los derechos del Estado y las obligaciones de los ciudadanos.

\section{"Con la llegada de los radicales al poder se inicia la eliminación de buena} parte de los impuestos que caracterizaron el período español y el surgimiento de la tributación directa en Colombia, manteniendo sólo tres grandes impuestos, a saber: aduanas, las salinas $y$ el papel sellado. 
66... se puede identificar a lo largo de la historia tributaria del país la alta dependencia de la tributación directa, donde se evidencia los altos niveles de fraude y evasión fiscal, no sólo por los contribuyentes sino por los administradores de los mismos.'
El resultado de la adopción de la tributación directa en Colombia hizo los ingresos fiscales menos dependientes de la tributación indirecta como había ocurrido en la primera parte de la vida republicana, la cual creaba y estimulaba en forma permanente la crisis fiscal del Estado"21.

En 1918, con la firma del entonces ministro de Hacienda Pomponio Guzmán, se dio vida normativa al impuesto sobre la renta en Colombia y al inicio de la "revolución" en las finanzas colombianas. Hay que señalar que esa revolución tuvo como contexto más amplio la "Regeneración" en curso desde la Constitución de 1886. El nacimiento y los primeros desarrollos del impuesto sobre la renta coinciden con sucesos de enorme importancia como el final de la Primera Guerra Mundial y el gran crac acaecido entre 1929-1933 que postró las economías mundiales. Este primer período fue característico de la llamada "República Liberal".

Por esta época Colombia vive un período de prosperidad, en cuanto que consigue ingresos a través de créditos externos y recursos provenientes de la indemnización que recibe de Estados Unidos por el Canal de Panamá, los invierte en infraestructura vial y ferroviaria e inicia su proceso de industrialización.

Según Fajardo y Suárez (2010), con la Ley 56 de $1918^{22}$ se configuraron ya varias de las principales características del impuesto, a saber: la universalidad de aplicación y el principio de residencia, la exención de una renta mínima, descuentos y exenciones por la actividad del sujeto del impuesto. Asimismo, durante este primer período se incorpora el concepto de renta líquida y se desarrolla el criterio de las tarifas marginales que se mueven entre $1 \%$ y $8 \%$; la retención en la fuente y el concepto de las devoluciones; y su recaudo se distribuyó entre los diferentes niveles de gobierno.

\footnotetext{
21 Ibíd.

22 www.dian.gov.co/dian/15servicios.nsf.
} 
A partir de esa época hasta 2011 , en la historia de nuestro país se encuentra que este impuesto ha sufrido innumerables reformas durante los diferentes períodos presidenciales; donde más reformas sufre es en la administración de Álvaro Uribe, todas tristemente buscando mejorar los ingresos tributarios y evitar la evasión en el recaudo del mismo impuesto. Sin embargo, se puede identificar a lo largo de la historia tributaria del país la alta dependencia de la tributación directa, donde se evidencia los altos niveles de fraude y evasión fiscal, no sólo por los contribuyentes sino por los administradores de los mismos.

El sistema tributario de Colombia cambia radicalmente a partir de 1942 y años siguientes, con la opción de incorporar nuevamente impuestos indirectos, entre ellos se destaca el impuesto a la ventas.

Según Fajardo, Donneys y Cabal (2008), en nuestro país el impuesto sobre las ventas apareció por primera vez como tal (la alcabala y la Armada de Barlovento representan sus antecedentes históricos descritos de la época de la Nueva Granada) cuando el gobierno de Eduardo Santos, mediante Decreto 1361 de 1942, decidió crear "Un gravamen equivalente al tres por ciento (3\%) del valor de las ventas realizadas por algunos establecimientos industriales como fábricas de hilados y tejidos de algodón, ingenios azucareros, fábricas de cerveza y cemento, entre otras. Dicho impuesto, creado a través del Decreto Extraordinario No. 1361 de 1942, debía ser pagado directamente por los establecimientos industriales y se liquidó de acuerdo con las declaraciones trimestrales que debían presentar a las administraciones de Hacienda Nacional".

Posteriormente el Congreso Nacional suprimió el impuesto antes creado, a partir del 1 de enero de 1943, mediante la inclusión de un artículo en la Ley 45 de diciembre 18 de 1942. Del impuesto anterior no se conservan datos significativos, aparece nuevamente en la década de 1960.

En 1963 con la Ley 21 se creó el impuesto a las ventas, pero entró en vigencia a partir de enero de 1965. El impuesto se caracteriza por ser monofásico. Se genera a través de la venta en cabeza del último productor, el cual podía hacer deducciones por compras a comerciantes de insumos y materias primas gravadas utilizadas en el proceso de producción, y desde este inicio la compensación se hacía directamente por el método de impuesto contra impuesto, situación que debería verse reflejada en la contabilidad de producción y venta.

Las reformas hechas después de 1965 permiten que el impuesto a las ventas se aproxime cada vez más a un impuesto al valor agregado que hoy se cobra en muchos países al igual que en España. A partir de ésa época ha representado una de las fuentes de ingresos más representativas en el sistema tributario actual, junto con el vigente impuesto de renta.

De igual forma encontramos como impuestos que se generaron para mejorar los ingresos de fuente nacional los impuestos de timbre, el de remesas, al patrimonio y el más reciente al gravamen a los movimientos financieros. Actualmente los dos últimos están reglamentados como de carácter transitorio y se eliminó gradualmente el de timbre, que era de los que quedaban como vestigios representantes de la época de la Colonia, y se elimina en el año 2006 el de remesas.

El impuesto de timbre se introdujo como impuesto de papel sellado y timbre, considerado dentro de las "rentas estancadas". El impuesto de timbre en Colombia en esencia fue tributo documental, ya que recaía sobre los documentos públicos o privados en los que se hacía constar la constitución, existencia, modificación o extinción de obligaciones; hoy queda como impuesto de timbre en algunos documentos y en el de registro y anotación.

Hoy el sistema tributario de nuestro país contempla una organización territorial de los mismos y siguen siendo la fuente principal de sus ingresos y conformación de la hacienda pública. Según Fajardo y Suárez (2010, pp. 22-23), para su control y recaudo el sistema tributario actual 
ha establecido diferentes impuestos de carácter nacional y territorial. En esta clasificación encontramos:

a) Impuestos nacionales: Los impuestos nacionales son aquellos que establece el Estado y cuya regulación y control están bajo diferentes dependencias de la administración del Estado y en algunos de ellos, el control está bajo las directrices de la DIAN (Dirección de Impuestos y Aduanas Nacionales); entre otros, se encuentran:

- Impuesto sobre la renta

- Impuesto al valor agregado a las ventas (IVA)

- Impuesto al patrimonio

- Impuesto al gravamen financiero

b) Impuestos departamentales: Los impuestos departamentales son aquellos que tiene establecido el Estado a través de leyes, las cuales deben ser compiladas a través de ordenanzas departamentales para que su administración, fiscalización, liquidación oficial, discusión, cobro, recaudo y control del impuesto estén bajo las directrices de cada una de las unidades administrativas de los diferentes departamentos de Colombia.

Desde la Constitución de 1886 se establecían tributos cuya explotación era exclusiva de las ciudades y los departamentos. La Constitución de 1991 también dejó esto muy claro y dentro de su articulado protegió las rentas municipales. "Constitución Política de Colombia, artículo 362. Los bienes y rentas tributarias y no tributarias o provenientes de la explotación de monopolios de las entidades territoriales, son de propiedad exclusiva y gozan de las mismas garantías que la propiedad y renta de los particulares".

Como impuestos de carácter departamental, encontramos:

- Impuesto de vehículos.

- Impuesto de registro y anotación.

- Impuesto al consumo de cigarrillo, cervezas, tabaco y licores.

- Impuesto a la gasolina motor y ACPM.

- Premios de loterías.

- Otros.

c) Impuestos municipales: Los impuestos municipales son aquellos que tiene establecido el Estado a través de leyes, las cuales deben ser compiladas en Acuerdos municipales de los Concejos, para que su administración, fiscalización, liquidación oficial, discusión, cobro, recaudo y control del impuesto estén bajo las directrices de cada una de las unidades administrativas de los diferentes municipios del país. Entre estos impuestos se destacan:

- Impuesto de Industria y Comercio

- Impuesto Complementario de Avisos y Tableros

- Impuesto Predial Unificado

- Impuesto a la Delineación Urbana

- Impuesto de Publicidad Exterior Visual

- Impuesto de Azar y rifas

- Impuesto de Espectáculos Públicos

- Impuesto de Degüello de Ganado

\section{CONCLUSIONES}

- Las instituciones tributarias que España estableció durante la colonización, tenían como finalidad obtener el mayor beneficio económico sin tener en cuenta el desarrollo y bienestar de los habitantes de las colonias.

- El incremento de las obligaciones tributarias y el trato discriminatorio por parte de los españoles generaron descontento entre los habitantes de las colonias, motivación principal y causa de la independencia.
- Dos de los impuestos que tienen su origen en la baja Edad Media y que hacían parte del sistema tributario español durante la época han evolucionado hasta llegar a la época actual, estos son: el almojarifazgo y la alcabala; el almojarifazgo es el equivalente al arancel de aduanas y la alcabala representaba el IVA.

- El impuesto de timbre es uno de los más antiguos del mundo. Fue traído en la época de la Colonia por España, desde entonces 
se incorporó como fuente de ingresos para el fisco y se configuró como el análogo al impuesto de papel sellado y estampillas de timbre nacional y el de Derechos de Registro. Hoy es el único vestigio que queda del impuesto de timbre.

- En la época de la Independencia la estructura tributaria se basaba principalmente en los ingresos provenientes del comercio exterior, los diezmos, tabacos, aguardientes, amonedación, correos, salinas, pólvora, papel sellado, venduta, alcabala para bienes extranjeros y bienes raíces. Posteriormente se crea la contribución directa, que si bien se reglamentó por los forjadores de la República entre 1819 y 1821, sólo un siglo después se implementó como el actual impuesto a la renta.

- En los sistemas tributarios del país se han reglamentado impuestos de carácter directo e indirecto. El impuesto directo que representa los mayores ingresos tributarios es el impuesto de renta y el impuesto indirecto sobresaliente es el impuesto a las ventas.

- Los sistemas tributarios han evolucionado en el país, apoyados en las diferentes constituciones políticas, y hoy son diferentes los impuestos que se cobran a favor del Estado, están reglamentados como de carácter nacional y territorial, para facilitar su recaudo y distribución desde sus órganos de control.

\section{BIBLIOGRAFÍA}

Araque Cárdenas, José Hilario (2008). Conceptos básicos de tributación. Neiva - Huila, Colombia: Universidad Sur Colombiana - Facultad de Economía y Administración - Programa de Contaduría Pública. Consultado el 14 de septiembre de 2011. Disponible en: http://www.araqueasociados.com/ es/Conceptosbasicosdetributacion.pdf.

Fajardo Calderón, Constanza Loreth y Suárez Amaya, Dora Cecilia (2010). El impuesto de renta. Obligaciones fiscales. Personas naturales - personas jurídicas. Bogotá: Editorial Kinesis.

Jaramillo Uribe, Jaime (1987). "La economía del Virreinato (1740-1810)", en: Ocampo, José Antonio (comp.). Historia Económica de Colombia. Bogotá: Fedesarrollo - Siglo XXI Editores, 77-78.

Kalmanovitz, Salomón (2008). Consecuencias económicas del proceso de Independencia en
Colombia. Bogotá: Fundación Universidad de Bogotá Jorge Tadeo Lozano.

López Garavito, Luis Fernando (1992). Historia de la Hacienda y el tesoro en Colombia. Bogotá: Banco de la República.

Pombo, José Ignacio de (1807, 18 de abril). "Informe del Consulado de Cartagena sobre asuntos económicos y fiscales (1920)", en: Boletín de Historia y Antigüedades, año XIII, No. 154, 689-698.

Restrepo, Juan Camilo (2001). Hacienda Pública, en ingresos fiscales. Bogotá, Colombia.

Tirado, Álvaro (1977). Introducción a la Historia Económica de Colombia. Medellín: La Carreta.

Tovar, Hermes (1987). "La lenta ruptura con el pasado colonial (1810-1850)", en: Ocampo, José Antonio (ed.). Historia Económica de Colombia. Capítulo III, Bogotá: Fedesarrollo - Siglo XXI, 91-94. 
